\title{
Some Medical Aspects of Long Range Penetration
}

\author{
Capt H W W Good, \\ RAMC \\ RMO 4th Bn The Border Regt (September 1944)
}

Editor's Note: The following notes were intended as a help to platoon commanders operating with LRP troops and wê?. the result of observations made on six months LRP training and fifteen weeks operations with a column of 23rd Brit Infantry Brigade in the Naga Hills. The operations, particularly from the point of view of treatment and evacuatior: casualties, differed from those of the Brigades who were operating inside Burma itself owing to the nature of the terrain, but the basic problems, particularly from the platoon commander's point of view, were the same. The author's views nay still be of interest today after more than 40 years.

\section{General Remarks}

Unless the Long Range Penetration (LRP) column becomes involved in a major action the problem of sickness is far greater than that of battle casualties. The statistics recently given for sickness casualties in the 14th Army show that malaria is a far greater enemy than the Jap. From the LRP platoon commander's point of view this is of far greater importance than when there are established lines of communication. It is of importance not only in respect of malaria but also of all other sickness encountered in jungle warfare.

The reasons are:

1. One cannot rely on the Column remaining static long enough for a man to receive a proper course of treatment.

2. One cannot expect to make an airstrip for every case of malaria, dysentery etc which occurs.

3 . The column must get on and the last thing one wants to do is to leave a man in a village if he can possibly make it under his own steam or be brought along by one or other of the means suggested later on in these notes.

It is obvious then from the very start that a different attitude has to be taken towards sickness on LRP than is taken in any form of operations where one can either evacuate a sick man or can hold him in a sick-bay long enough to get him on his feet again.

From a technical point of view, the scale of drugs and equipment on issue to the MO of an LRP column is better and more varied than anything I have yet seen on issue to Regimental MOs or even Field Ambulances. Practically every known complaint is catered for and the only thing it is impossible to prescribe is rest.

What then can be done to keep a sick man going when it is impossible to give him the necessary rest?

In my opinion the keynote is fighting fitness, good morale and discipline, and good officers. I will deal with these two points separately and try to show how they affect sickness.

1. Morale, Discipline. If a man's morale is good when he feels off colour, instead of giving in to his complaint he will endeavour to carry on cheerfully, particularly if he is in the middle of a strenuous day's march, and will come along to the RAP when he gets to a halt, take his medicine and try to pull round. Another man whose morale is not so good may drop in his tracks, as a resw th of which the column will either have to be halted orat least strung out, which is tactically undesirable. IE is amazing what the human frame can stand up to under stress, and if a man can be persuaded to carry on eren though he feels temporarily 'groggy', in 99 cases out'of 100 he will get to his destination under his own stealm and be none the worse.

2. Good Officers. From a medical point of view a d officer is one who knows his men, and by this I gort't mean that he knows if a man is married, how children he has, what he did in "civvy street" and sब. The only way one can know a man from a fitness pow of view is to study the sick reports during the trayjigg period. It never fails to tell a man's physical fitnese and character. A man may be admitted to hospital Hinee times during the training period with malaria and the he may still be considered $\mathrm{A} 1$ and may even proceed

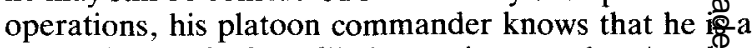
man to be watched as a likely genuine casualty. Anotiper man may be on the sick report regularly during Gie whole training period with a multitude of minor complaints, and he can usually be marked down as habitual scrounger and one who has to be driven rather than encouraged. The sick report is therefore a

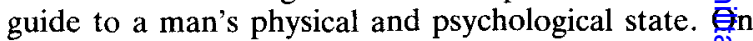
LRP it is more than ever necessary for an officer to shộ an example to his men. If you are feeling groggy go aloficg and see the MO at one of the long halts and get some medicine and make yourself carry on, and you will fiñ that the bulk of your men will do the same. You are afso in a better moral position to drive on the unwilling.

\section{Training}

The training period is the time to educate your mengn the correct attitude to be taken towards illness when LRP. It can be pointed out to them that no matter haw groggy they may feel there is usually no option butnoo carry on. In almost every case of sickness on the marchit is possible to have a man's pack carried on a mule. Th\&e is a limited number of ponies in the column for the carriage of sick and wounded. In the main a man has?o 
be prepared to foot it without a pack. The maxim I used to lay down in lecturing troops was that as long as a man is conscious, is not in severe pain and has no impediment of locomotion such as a severe injury to leg or foot he will keep marching. This may seem harsh treatment but it is the way it has to be put to the men in training. The reason for putting it so strongly is to be able to give the benefit of what transport is available to the more ill men and not to be encumbered with the less ill but weaker willed ones. I have also pointed out to the men that they may expect efficient medical treatment from the MO but that sympathy is a commodity which one cannot afford to dispense on LRP columns.

Water sterilization is a thing which must be hammered into the men. On training, in order to conserve supplies of sterilizing tablets I have usually adopted the method of platoon group sterilization with chlorinating powder. This method not only ensured that chlorination of drinking water was carried out in training but also, by making a drill of it, water sterilization became automatic when the men carried it out individually on operations.

Anti-malaria precautions must be carried out to the letter in training though they had to be modified slightly on operations. It is quite impossible to prevent all cases of malaria occurring but by carrying out full precautions the incidence is greatly reduced. We carried our mosquito nets during the whole training period. The slight increase in weight due to carrying the net was worth it.

As far as first aid training for non-medical personnel is concerned I recommend the pamphlet which I am attaching to these notes*. It is the best first aid instruction $I$ have yet seen and contains everything necessary for non-medicals. I have therefore no intention of going further into the subject of first aid except to point out that whereas early treatment of all casualties is desirable, the amount of "flap" usually created even by a minor wound or injury is helpful neither to the patient nor to the medical orderly and usually entirely unnecessary. In other words if you have no medical orderly, carry out the suggestions laid down in the pamphlet to the best of your ability and if you have an orderly don't interfere with him but give him any assistance he may require.

The establishment of medical orderlies at present on LRP column is totally inadequate and it has been found necessary to employ regimental personnel on this work. It is usually simple enough to find men who have had Stretcher Bearer Training, as there is usually a number of men in the column who have been SBs when the unit was an orthodox battalion establishment. The difficulty is that they are on the column establishment as No. 2 on the Bren, section leaders and so on, but if they are required for the benefit of the platoon to do medical work it has usually been found necessary for their other operational role to take second place. In this way we have ensured that every platoon has someone who can be relied upon to attend to casualties and minor ailments and someone who has a working knowledge of medical orderly work. I consider the original training suggestion of having the platoon commander carry out his own sick parade as pure bunkum. The new establishment may possibly provide for an increase in medical orderlies which will solve the problem.

As regards sickness and accidents in training I advise you to make as much use as possible of the Medical Services as you think necessary, and if you are satisfied that a man is genuine, don't at this stage take all the responsibility but "pass the buck" on to the MO. The time will come on operations when you will find it necessary to carry out harsh treatment but in training it is liable to cause administrative difficulties. Preach toughness as much as you can but only carry it out on operations. The MO will deal with any slackers during the training period.

One more point; if a man falls out on the march let the orderly see him. If he thinks the man is not too bad leave one man only to see that the sick man makes his destination in his own time. If the man has had an injury or becomes seriously ill, the orderly will be able to judge and then it may be necessary to leave a carrying party to assist the MO when he comes up with Rear Col HQ. Never leave your orderly behind for he may not catch up with you again and you have 39 other potential casualties in your platoon. For a similar reason never leave an NCO behind - you need all the NCOs you have.

The only other subject of importance from a medical point of view in training is personal hygiene and sanitation. There is little to be said on personal hygiene which is not to be found in all basic military training. See that the men bathe themselves when possible and encourage them to wash their clothes occasionally while out on training.

Care of the feet can be included under this heading. Forget about brine baths, methylated spirit and powder and other suggestions laid down in various instructions on care of the feet. Apart from a few men who suffer from chronic foot infections and disabilities, most men's feet become hardened with the continuous marching of LRP and apart from the first few week's training when one gets the usual stream of blisters after a day's march there is little foot trouble. Make the men wash their feet regularly and dry them well. Try to let them change their socks after a wet day's marching or after a river crossing. Some officers and men on a column gave up wearing socks and this is quite feasible; I did not do it personally but the advantages are that lost or damaged socks are no impediment to efficient marching and the bogey of wet socks is surmounted. They also said the feeling of comfort on changing into socks and PT shoes in the evening was much more marked than if they had worn socks all day.

Finally a word about sanitation. When you get to a bivouac area for a long halt or for a period up to $48 \mathrm{hrs}$ try and arrange for a small latrine to be dug in your platoon area. Remember that other troops on training may select just the same area in which to bivouac later. 
Fill in the latrine before leaving the bivvy area. Make it a drill that no man goes for a "rear" during a halt on the march or in an area where a latrine is impracticable unless he brings a digging implement. It is very desirable from a sanitation point of view and very necessary from a security point of view. The Intelligence Section will tell you all about the inadvisability of using your old correspondence as latrine paper. Lastly, never permit a man to have a "rear" within 100 yards of a water point.

These points I think cover all eventualities during the training period and I will now try to give you some useful advice for operations.

\section{Operations}

Medical problems will take a major place amongst the difficulties you will encounter on operations. You will usually be with the main body of the column, when many of your problems can be solved by the MO or you may be on a patrol with your platoon anything up to three days march away from your column with just your medical orderly. You can count on your men having a host of minor ailments mainly stomach ache, diarrhoea, vomiting and loss of appetite. You will soon begin to consider these as necessary accompaniments of operations which entail physical strain greater than anything else you have ever endured and rations which though reasonably adquate, are monotonous and not entirely satisfying. As the campaign drags on you will have more definite types of illness occurring - malaria and dysentery being the commonest. Whether you have many battle casualties or not depends on circumstances but your sickness rate is almost certain to be many times greater than your battle casualty rate unless you are by some mischance beaten up.

While with the column do as much as you can to relieve the strain on the MO. Your orderly will have a very varied selection of drugs, lotions and dressings etc., and unless the Column is static for a period it is best that the orderly treats all your cases, only referring to the MO those cases he considers require more skilful attention. Make yourself acquainted with the appearance of a man having a typical attack of malaria. If there is anything interesting in the way of a skin rash, have a look at it. If possible have a look at all wounds your men may have. By this means you will become accustomed to seeing what may previously have seemed very frightening conditions and you will not get into a "flap" over them.

Insist on strict march discipline, water discipline and anti-malaria precautions and latrine discipline. Each man carries an individual water sterilizing outfit. See that he uses it and make sure that your platoon supplies of sterilizing tablets are never exhausted. This also applies to your suppressive mepacrine tablets which are supplied in small containers to individuals. One tablet is taken daily during the whole of the operations. It is highly effective in suppressing malaria during the fi six to eight weeks of operations and although after this its effectiveness diminishes it still prevents any massive numbers of malaria cases breaking out and keeps manyy potential casualties on their feet. Make sure to dispel the rumour which always starts amongst the men that mepacrine makes a man sterile. I can assure you such is not the case. We do not carry mosquito nets on operations. Head veils were carried but were unsatisfactory. A new type of head veil may be produced for future operations. The anti-mosquito cream with vanishing cream base is a great improvement on the gid type and causes little of the discomfort experienced with the old type. "Scat", a liquid insect repellant, is sometimes available on supply drops and is vefy efficient.

Given normal conditions where early evacuation casualties is desirable or where a number of sick haj accumulated so as to impede the mobility of the columin, a light plane strip is constructed and the casualtits evacuated direct from the column to air base. If a Brigade stronghold has been formed and casualties occur within the stronghold or within a reasonate carrying distance of the stronghold, evacuation is ufen possible by transport plane. In the case of the $23 \mathrm{Br}$ ade operations, owing to the nature of the country, ifves generally not possible to construct light plane strips column constructed two only, and by the time theyerte completed the Column had to move on. They wyege however, used for evacuation by the BrigadeofHQ Column. It was generally necessary then to dispatch. Oir cases back to the nearest airstrip or "jeep heas coolie bearers. This often meant a carry of up to the days but the coolies were magnificent. If it is explaind to a village headman what exactly is required he fill have the stretcher constructed and lay the whole thî. on. We were fortunate in that the Naga hillmen were $100 \%$ loyal and I can't say if the same thing is applica to the Burmese villagers. If there is any doubt as to the loyalty of the villagers it is generally found possible 30 send an escort but this further reduces your manpower. In the event of it being found impossible owing to enemy action to evacuate your casualties thus, and a impossible to construct a light plane strip, you should $\$ y$ every means of carrying your casualties with you, evenif it is uncomfortable for the wounded man, but it must remembered that hand carrying by stretcher bearer is one of the most exhausting tasks imaginable. As a fogst resort where delay is likely to cost more lives or cause the failure of an alloted task, the casualty or casualities must be left in the nearest village under the care of village headman, with money and as much rations, dragss and dressings as can be spared. There is a form in which can be given to headman, with instructions to take good care of the injured, conceal him from the Japansse and hold him until it is possible to hand him over to party of British troops. 
"Do's and Don't's for Platoon Commanders on Detachment from the Column

Don't "flap" as soon as you get a casualty either from wounds or sickness. Do take your medical orderly's advice and give him all possible assistance. Don't "packin" yourself if you feel ill as long as you can possibly force yourself to keep going. Go and see the MO as soon as he rejoins your Group. Don't have your pack carried for you unless you are ill or unless every man of your platoon is having his carried. Don't carry "buckshee" rations either on your person or on a pack animal. In the event of a headman bringing you gifts of food do your best to see that he provides like gifts for all your platoon.

Don't evacuate any casualties unless you are certain of their ultimate safety and unless they have a good chance of survival.

Don't forget that you are in wireless communication with your Column HQ and can get advice from the MO over the air.

Don't exhaust your men on the march merely to keep up to a time standard laid down during training. In the Naga Hills it was often not possible to march more than 15 mins at a stretch and then we had to rest for 15 mins.

\section{Conclusion}

In conclusion I would like to point out that many of the opinions voiced in these notes are controversial and are merely my own personal opinions. I feel, however, that results prove whether the methods adopted are good or otherwise. Our column of the Border Regt operated with 23 British Infantry Brigade from April 10 to July 19 . We marched and fought from Mariani on the Bengal-Assam Railway, N E of Dinapur to Imphal, through Mokochung, Gaziphema, Karasom and Uhkrul in some of the most mountainous country in the world. At times the platoons were operating up to as much as 40 miles from Column $\mathrm{HQ}$ and they invariably had to return at least 20 of those miles to rejoin the Column. On many of the raids it was impossible to take pack animals. We started some 400 strong and arrived at Imphal less two officers and 23 ORs. Of these, one officer and five ORs were killed and one officer and six ORs wounded. I think these figures speak for themselves as the remaining 12 men were the only cases evacuated through illness.

\section{HONORARY CONSULTANTS TO THE ARMY}

Mr C E Polkey, MD, FRCS, has been appointed Honorary Consultant in Neurosurgery to the Queen Elizabeth Military Hospital with effect from 10 December 1985.

Dr J W G Smith, MD, FRCPath, FFCM, FI Biol, Dip Bact, has been appointed Honorary Consultant in Vaccination and Immunisation to the Army with effect from 1 December 1985. This is a new appointment. 